\title{
Penggunaan Metode Branch and Bound dan Gomory Cut dalam Menentukan Solusi Integer Linear Programming
}

\author{
Wahyudin Nur ${ }^{1}$, Nurul Mukhlisah Abdal ${ }^{2}$ \\ ${ }^{1}$ Program Studi Matematika FMIPA Universitas Sulawesi Barat \\ ${ }^{2}$ Jurusan Matematika FMIPA Institut Teknologi Bandung \\ e-mail: $\underline{{ }^{1} \text { wnalafkar93@gmail.com }}, \underline{{ }^{2} \text { nurulmukhlisah@gmail.com }}$
}

\begin{abstract}
Abstrak
Integer Linear Programming adalah sebuah model matematis yang memungkinkan hasil penyelesaian kasus pada Pemrograman Linier berupa bilangan bulat. . Masalah integer linear programming termasuk salah satu bagian riset operasi yang sangat penting karena dalam kehidupan sehari-hari, ada banyak permasalah pemrograman linear yang mengharuskan solusinya integer. Ada beberapa metode untuk menyelesaikan persoalan Integer Programming, tapi yang akan dibahas pada penelitian ini adalah Metode Branch and Bound dan Metode Gomory Cut. Tujuan dari penelitian ini adalah untuk menentukan solusi masalah Integer Linear Programming dan membandingkan hasil yang diperoleh dari Metode Branch and Bound dengan Metode Gomory Cut. Penelitian ini adalah penelitian kepustakaan yang menggunakan berbagai literatur-literatur yang berkaitan dengan topik yang akan diteliti. Hasil penelitian ini menunjukkan solusi yang diperoleh dari metode Branch and Bound samadengan metode Gomory Cut. Dalam pemecahannya metode Branch and Bound memerlukan banyak iterasi simpleks dibanding metode Gomory Cut.
\end{abstract}

Kata kunci: Integer Linear Programming, Metode Branch Bound, Metode Gomory Cut

\section{PENDAHULUAN}

Riset Operasi adalah salah satu bagian matematika yang mengkaji cara menetapkan arah tindakan terbaik (optimum) dari sebuah masalah keputusan di bawah pembatasan sumber daya yang terbatas. Pada tahun 1947 seorang ahli matematika dari Amerika Serikat yang bernama George D. Danzig menemukan cara untuk menguraikan dan memecahkan persoalan pemrograman linear dengan Metode Simpleks (Simplex Method). Ia menguraikannya dalam buku yang berjudul Linear Programming and Extension. Keberhasilannya karena mampu menyelesaikan berbagai masalah dalam kehidupan nyata seperti di bidang militer, industri, pertanian, transportasi, ekonomi, kesehatan, dan ilmu sosial.

Pada kenyataannya, tidak semua masalah seperti di atas bisa diselesaikan dengan metode yang biasa digunakan dalam menyelesaikan $L P$, terutama jika beberapa atau semua variabel yang telah dimodelkan untuk memiliki nilai-nilai bulat (integer), misalkan kita ingin menentukan kombinasi jumlah produksi kursi dan meja. Kasus ini tidak dapat diselesaikan langsung dengan metode $L P$ biasa sehingga diperlukan metode khusus yang dipadukan dengan metode penyelesaian $L P$ sehingga dapat memaksa solusi kasus tersebut mengarah kepada solusi integer.

Bakhtiar S. Abbas (2008) dosen jurusan Teknik Industri, Fakultas Teknik, Universitas Bina Nusantara dalam penelitiannya "Sistem Optimasi Optimalisasi Produksi untuk Memaksimalkan Laba" mengatakan masalah yang dihadapi perusahaan saat ini adalah ketidakmampuan perusahaan dalam menentukan jumlah produksi optimal. Hal itu mengakibatkan perusahaan seringkali mengalami kekurangan dan kelebihan produksi yang 
JURNAL SAINTIFIK VOL.2 NO.1, JANUARI 2016

menyebabkan perusahaan tidak dapat mencapai laba maksimum. Metode yang dia gunakan dalam menghitung unit produksi untuk mencapai laba maksimum adalah Metode Branch and Bound. Dalam penelitiannya beliau menyelesaikan suatu permasalahan yang melibatkan banyak variabel dan fungsi kendala. Karena menurutnya metode inilah yang lebih bersifat umum dibanding dengan metode lain karena keakuratannya dalam menentukan solusi ILP. Dalam penelitian ini, selain membahas mengenai metode Branch and Bound, penulis juga akan memperkenalkan metode yang agak jarang digunakan yaitu metode Gomory Cut.

\section{METODE PENELITIAN}

Dalam penelitian ini, penulis menggunakan metode kajian pustaka (studi literatur), yaitu penelitian yang bertujuan untuk mengumpulkan data dan informasi dengan bantuan bermacammacam material yang terdapat di ruang perpustakaan, seperti: buku-buku, jurnal, dokumentasi, catatan, dan juga internet. Adapun langkah-langkah yang dilakukan dalam penelitian ini adalah: 1) mencari referensi yang berkaitan dengan masalah Integer Linear Programming dan metodemetode untuk menentukan solusinya 2) memilih beberapa metode yang akan dibahas secara rinci dalam menentukan solusi Integer Linear Programming yaitu metode Branch and Bound dan Metode Gomory Cut 3) mencari referensi yang berkaitan dengan metode yang berkaitan dengan metode Branch And Bound dan metode Gomory Cut 4) memahami alur pikir metodemetode tersebut dalam menentukan solusi Integer Linear Programming 5) mencari referensi penunjang.

\section{HASIL DAN PEMBAHASAN}

Pada bab ini akan dibahas mengenai penggunaan metode Branch and Bound dan Gomory Cut dalam menentukan solusi optimal terhadap permasalahan yang berkaitan dengan Integer Linear Programming. Misalkan sebuah perusahaan PT. Lightning merakit 3 jenis senter. Senter jenis A, senter jenis B, dan senter jenis C. Senter jenis A dirakit dengan membutuhkan waktu 3 menit, jenis B selama 8 menit dan jenis C selama 5 menit. Waktu pengerjaan yang tersedia tiap minggunya selama 1500 menit. Senter jenis A membutuhkan besi seberat $9 \mathrm{~g}$, senter jenis B membutuhkan besi seberat 6 gram, dan senter jenis $C$ membutuhkan besi seberat 7 g. Jumlah besi yang dapat disediakan oleh perusahaan hanya 2000 gram tiap minggunya. Untuk senter jenis A membutuhkan aluminium seberat $5 \mathrm{~g}$, senter B membutuhkan aluminium seberat $3 \mathrm{~g}$, dan senter $\mathrm{C}$ seberat $8 \mathrm{~g}$. Jumlah aluminium yang dapat disediakan oleh perusahaan tiap minggunya mencapai 1800 gram. Jika keuntungan bersih yang diperoleh dari hasil penjualan senter A, senter B, senter C berturut-turut sebesar Rp 9000, Rp 7000, Rp 8000. Berapa kombinasi dari ketiga senter ini yang harus diproduksi sehinnga keuntungan dapat maksimum.

Kasus di atas dapat dimodelkan kedalam bentuk pemrograman linear, yaitu

$$
\begin{aligned}
& z=9 x_{1}+72+8 x_{3} \\
& 3 x_{1}+8 x_{2}+5 x_{3} \leq 1500 \\
& 9 x_{1}+6 x_{2}+7 x_{3} \leq 2000 \\
& 5 x_{1}+3 x_{2}+8 x_{3} \leq 1800 \\
& x_{1}, x_{2}, x_{3} \geq 0 \\
& x_{1}, x_{2}, x_{3} \in
\end{aligned}
$$

Persamaan $z$ dalam ribuan, selanjutnya kita mengubah persamaan di atas menjadi bentuk baku agar bisa diselesaikan dengan menggunakan metode simpleks. 


$$
\begin{aligned}
& z=9 x_{1}+7_{2}+8 x_{3}+0 s_{4}+0 s_{5}+0 s_{6} \\
& 3 x_{1}+8 x_{2}+5 x_{3}+s_{4}=1500 \\
& 9 x_{1}+6 x_{2}+7 x_{3}+s_{5}=2000 \\
& 5 x_{1}+3 x_{2}+8 x_{3}+s_{6}=1800
\end{aligned}
$$

\begin{tabular}{|c|c|c|c|c|c|c|c|c|}
\hline & $x$ & $x_{2}$ & $x_{3}$ & $S_{4}$ & $S_{5}$ & $s_{6}$ & \multirow{2}{*}{$\beta$} \\
\hline & & 9 & 7 & 8 & 0 & 0 & 0 & \\
\hline$S_{4}$ & 0 & 3 & 8 & 5 & 1 & 0 & 0 & 1500 \\
\hline$S_{5}$ & 0 & 9 & 6 & 7 & 0 & 1 & 0 & 2000 \\
\hline$s_{6}$ & 0 & 5 & 3 & 8 & 0 & 0 & 1 & 1800 \\
\hline$z$ & & 0 & 0 & 0 & 0 & 0 & 0 & 0 \\
\hline$c-$ & & 9 & 7 & 8 & 0 & 0 & 0 & \\
\hline
\end{tabular}

selanjutnya kita membuat tabel simpleks awal seperti yang terlihat di bawah ini:

Tabel 1. Tabel Simpleks Awal

setelah melakukan beberapa kali iterasi simpleks. diperoleh tabel optimum:

Tabel 2. Tabel Optimum

\begin{tabular}{|l|l|l|l|l|l|l|l|l|}
\hline \multicolumn{2}{|c|}{} & $x_{1}$ & $x_{2}$ & $x_{3}$ & $S_{4}$ & $S_{5}$ & \multirow{2}{*}{$S_{6}$} & \multirow{2}{*}{$\beta$} \\
\cline { 2 - 8 } & $\mathbf{9}$ & 7 & $\mathbf{8}$ & $\mathbf{0}$ & $\mathbf{0}$ & $\mathbf{0}$ & \\
\hline$x_{2}$ & 7 & 0 & 1 & 0 & $37 / 230$ & $1 / 230$ & $-12 / 115$ & $1430 / 23$ \\
\hline$x_{1}$ & $\mathbf{9}$ & 1 & 0 & 0 & $-27 / 230$ & $49 / 230$ & $-13 / 115$ & $1070 / 23$ \\
\hline$x_{3}$ & $\mathbf{8}$ & 0 & 0 & 1 & $3 / 230$ & $-31 / 230$ & $27 / 115$ & \multirow{2}{*}{$3970 / 23$} \\
\hline$z$ & & 9 & 7 & 8 & $4 / 23$ & $20 / 23$ & $3 / 23$ & \multirow{2}{*}{2234.78} \\
\hline$z-c$ & 0 & 0 & 0 & $4 / 23$ & $20 / 23$ & $3 / 23$ & \\
\hline
\end{tabular}

Dari tabel $1 \mathrm{di}$ atas, diperoleh hasil optimum $x_{1}=\frac{1070}{23}, x_{2}=\frac{1430}{23}, x_{3}=\frac{3970}{23}$ dan $z=2234,78$. Karena semua variabelnya bukan bilangan bulat, maka diperlukan metode khusus untuk menentukan solusi integernya yaitu metode Branch and Bound dan Gomory Cut.

\subsection{Metode Branch and Bound}

Metode Branch and Bound dapat digunakan untuk menyelesaikan masalah yang mengharuskan seluruh variabelnya merupakan bilangan bulat. Adapun langkah-langkah dalam menyelesaikan masalah memaksimumkan untuk kasus integer murni adalah sebagai berikut:

- Selesaikan kasus ILP dengan menganggap kasus tersebut seperti kasus LP. Dalam menentukan solusi $L P$ tersebut sebaiknya menggunakan metode simpleks.

- Apabila solusi optimal telah diperoleh dan semua variabelnya bilangan bulat maka solusi $L P$ tersebut menjadi solusi optimal ILP karena telah memenuhi semua syarat. Sedangkan apabila sebagian variabel bukan bilangan bulat maka pilih salah satu variabel tersebut untuk dilakukan percabangan (Branching) sehingga kita memperoleh 2 submasalah ILP.

- Selesaikan kedua submasalah tersebut seperti langkah pertama, dan dari kedua submasalah tersebut tentukan Upper Bound (Bounding). Upper Bound adalah solusi submasalah yang memiliki nilai tertinggi.

- Apabila submasalah yang solusinya menjadi Upper Bound belum memenuhi syarat integer maka kita melakukan proses percabangan (Branching) dan selesaikan submasalah tersebut seperti langkah ketiga. 


\section{JURNAL SAINTIFIK VOL.2 NO.1, JANUARI 2016}

Berdasarkan tabel 1, diperoleh hasil optimum $x_{1}=1070 / 23, x_{2}=1430 / 23, x_{3}=3970 / 23$ dan $z=2234,78$. Karena semua variabelnya noninteger, maka kita bisa memiilih salah satu variabelnya misal $x_{1}$ untuk dilakukan percabangan dan dijadikan kendala baru yaitu cabang I $\left(x_{1} \leq 6\right)$ dan cabang II $\left(x_{1} \geq 7\right)$. Setelah itu dicari solusi optimal dengan menggunakan iterasi simpleks, sehingga diperoleh solusi optimum dari tiap cabang. Prosedur ini diulang sampai semua variabelnya integer.

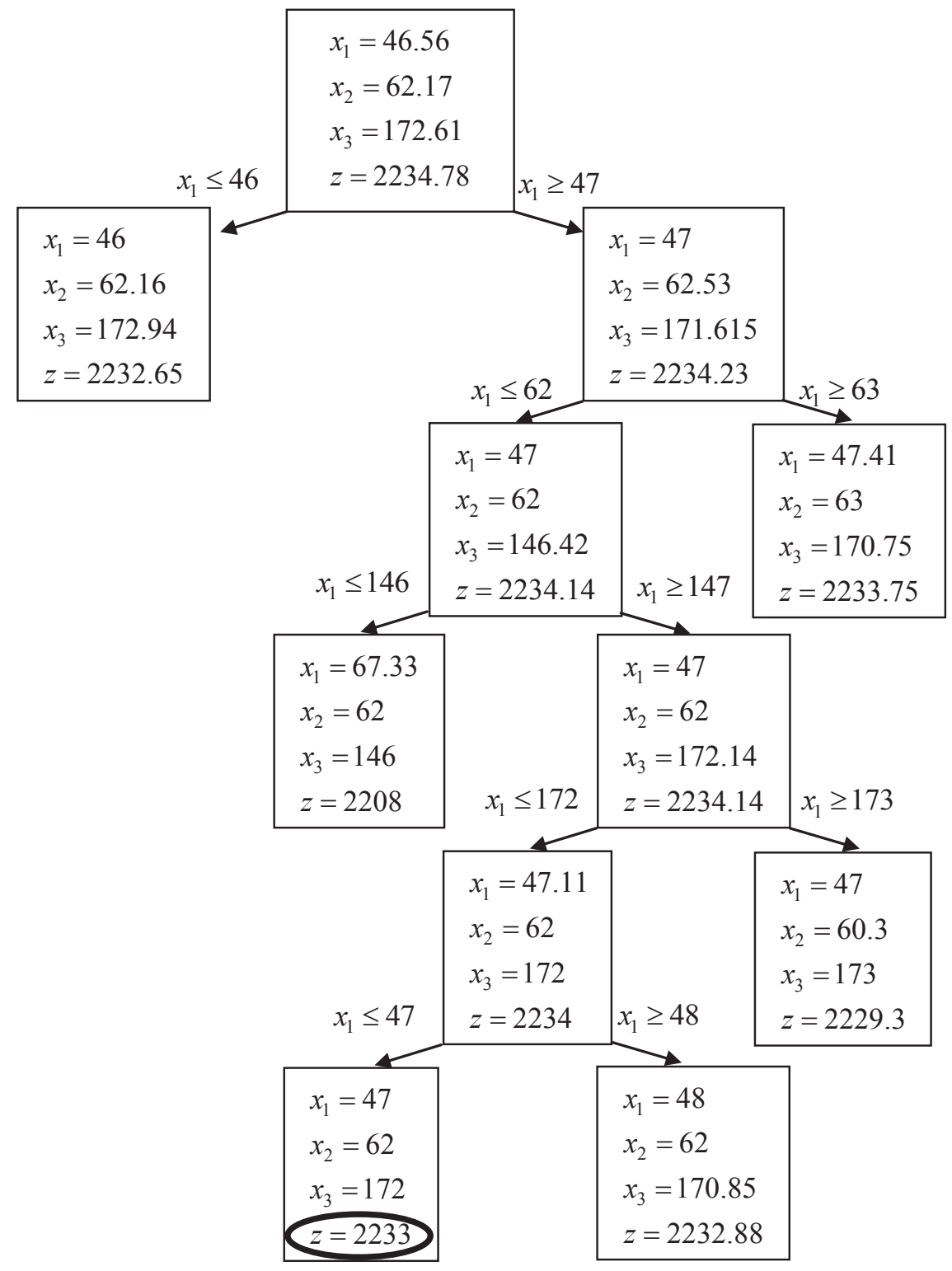

Gambar 1. Percabangan metode Branch and Bound

diperoleh solusi optimum $x_{1}=47, x_{2}=62, x_{3}=172$ dan $z=2233$. Sehingga dapat disimpulkan berdasarkan metode Branch and Bound, perusahaan tersebut harus memproduksi senter A 
sebanyak 47, senter B sebanyak 62 dan senter C sebanyak 172 agar menghasilkan keuntungan optimum 2.233.000.

\subsection{Metode Gomory Cut}

Variabel $x_{i}(i=1,2, \ldots, m)$ mewakili variabel dasar dan variabel $w_{j}(j=1,2, \ldots, n)$

mewakili variabel nondasar. Variabel-variabel ini telah diatur demikian untuk kemudian pertimbangkan persamaan ke-i dimana variabel dasar $x_{i}$ memiliki nilai noninteger.

$x_{i}=\beta_{i}-\sum_{j=1}^{n} \alpha_{i}^{j} w_{j} \quad \beta_{i}$ noninteger (baris sumber)

Setiap persamaan seperti ini akan dirujuk sebagai baris sumber. Karena, pada umumnya koefisien fungsi tujuan dapat dijadikan integer, variabel z juga integer dan persamaan $\mathrm{z}$ tersebut dapat dipilih sebagai baris sumber. Pada kenyataanya, bukti konvergensi dari algoritma ini mengharuskan $\mathrm{z}$ untuk berupa integer sehingga

$$
\begin{aligned}
& \beta_{i}=\left[\beta_{i}\right]=f_{i} \\
& \alpha_{i}^{j}=\left[\alpha_{i}^{j}\right]+f_{i j}
\end{aligned}
$$

Dimana $N=[a]$ adalah bilangan bulat terbesar sedemikian sehingga $N \leq a$ dan disimpulkan bahwa $0<f_{i}<1$ dan $0<f_{i j} \leq 1$. Adapun batasan yang nantinya akan ditambahkan pada tabel simpleks terakhir adalah

$$
S_{i}=\sum_{j=1}^{n} f_{i j} w_{j}-f_{i}
$$

Setelah memperoleh tabel simpleks yang baru, kita akan menentukan solusi optimum yang baru. Apabila solusi optimumnya masih ada yang berupa noninteger, maka dilanjutkan kembali dengan pemberian batasan baru dan begitu seterusnya.

Berdasarkan tabel 4.2, diperoleh hasil optimum $x_{1}=46 \frac{12}{23}, x_{2}=62 \frac{4}{23}, x_{3}=172 \frac{14}{23}$ dan $z=2234 \frac{18}{23}$. Karena semua variabelnya noninteger maka pemotongannya bisa menggunakan baris $x_{1}, x_{2}$ ataupun $x_{3}$ tetapi karena $f_{i}$ untuk baris $x_{3}$ adalah $\frac{14}{23}$ (paling besar) sehingga pemotongan akan dilakukan berdasarkan pada baris $x_{3}$, yaitu:

$x_{3}+\frac{3}{230} s_{4}+\left(-1+\frac{199}{230}\right) s_{5}+\frac{27}{115} s_{6}=172+\frac{14}{23}$

Jadi pemotongan gomory (Gomory $\mathrm{Cut}$ ) yang bersesuaian adalah

$$
\frac{3}{230} s_{4}+\frac{199}{230} s_{5}+\frac{27}{115} s_{6} \geq \frac{14}{23}
$$

$\frac{3}{230} s_{4}+\frac{199}{230} s_{5}+\frac{27}{115} s_{6}-s_{7}=\frac{14}{23}$

$$
-\frac{3}{230} s_{4}-\frac{199}{230} s_{5}-\frac{27}{115} s_{6}+s_{7}=-\frac{14}{23}
$$

Kendala baru ini dimasukkan ke tabel simpleks terakhir sehingga diperoleh tabel simpleks baru, yaitu: 
JURNAL SAINTIFIK VOL.2 NO.1, JANUARI 2016

Tabel 3. Tabel simpleks (penambahan kendala pemotongan gomory I)

\begin{tabular}{|c|c|c|c|c|c|c|c|c|c|}
\hline & \multirow{2}{*}{$\begin{array}{l}x_{1} \\
9\end{array}$} & \multirow{2}{*}{\begin{tabular}{|l|}
$x_{2}$ \\
7 \\
\end{tabular}} & \multirow{2}{*}{$\begin{array}{l}x_{3} \\
8 \\
\end{array}$} & \multirow{2}{*}{$\begin{array}{l}S_{4} \\
\mathbf{0} \\
\end{array}$} & \multirow{2}{*}{$\begin{array}{l}S_{5} \\
\mathbf{0} \\
\end{array}$} & \multirow{2}{*}{$\frac{s_{6}}{\mathbf{0}}$} & \multirow{2}{*}{$\begin{array}{l}S_{7} \\
\mathbf{0} \\
\end{array}$} & \multirow{2}{*}{$\beta$} \\
\hline & & & & & & & & & \\
\hline$x_{2}$ & 7 & 0 & 1 & 0 & $37 / 230$ & $1 / 230$ & $-12 / 115$ & 0 & $62 \quad 4 / 23$ \\
\hline$x_{1}$ & 9 & 1 & 0 & 0 & $-27 / 230$ & $49 / 230$ & $-13 / 115$ & 0 & $46 \quad 12 / 23$ \\
\hline$x_{3}$ & 8 & 0 & 0 & 1 & $3 / 230$ & $-31 / 230$ & $27 / 115$ & 0 & $172 \quad 14 / 23$ \\
\hline$S_{4}$ & 0 & 0 & 0 & 0 & $-\quad 3 / 230$ & $-199 / 230$ & $-27 / 115$ & 1 & $-14 / 23$ \\
\hline$z$ & & 9 & 7 & 8 & $4 / 23$ & $20 / 23$ & $3 / 23$ & 0 & \\
\hline$z-$ & & 0 & 0 & 0 & $4 / 23$ & $20 / 23$ & $3 / 23$ & 0 & \\
\hline
\end{tabular}

Tabel simpleks dual 3 di atas kemudian diselesaikan untuk memperoleh tabel optimum baru. Apabila solusinya masih noninteger, maka ulangi prosedurnya dengan melakukan pemotongan Gomory sehingga diperoleh kendala baru. Proses ini diulangi sampai diperoleh tabel simpleks optimum seperti di bawah:

Tabel 4. Tabel simpleks optimum (penambahan kendala pemotongan gomory IV)

\begin{tabular}{|c|c|c|c|c|c|c|c|c|c|c|c|c|}
\hline & & $\begin{array}{l}x_{1} \\
9\end{array}$ & $\begin{array}{l}x_{2} \\
7\end{array}$ & $\begin{array}{l}x_{3} \\
8\end{array}$ & $\begin{array}{l}S_{4} \\
\mathbf{0}\end{array}$ & $\frac{S_{5}}{\mathbf{0}}$ & $\begin{array}{l}S_{6} \\
\mathbf{0}\end{array}$ & $\frac{S_{7}}{\mathbf{0}}$ & $\begin{array}{l}S_{8} \\
\mathbf{0}\end{array}$ & $\begin{array}{l}S_{9} \\
\mathbf{0}\end{array}$ & $\begin{array}{l}S_{10} \\
\mathbf{0}\end{array}$ & $\beta$ \\
\hline$x_{2}$ & 7 & 0 & 1 & 0 & 0 & 0 & 0 & -1 & 0 & 0 & 1 & 62 \\
\hline$x_{1}$ & 9 & 1 & 0 & 0 & 0 & $8 / 9$ & 0 & $-1 / 9$ & 0 & 0 & $-2 / 3$ & 47 \\
\hline$x_{3}$ & 8 & 0 & 0 & 1 & 0 & -1 & 0 & 1 & 0 & 0 & 0 & 172 \\
\hline$s_{6}$ & 0 & 0 & 0 & 0 & 0 & $35 / 9$ & 1 & $-4 \quad 4 / 9$ & 0 & 0 & $1 / 3$ & $24 / 9$ \\
\hline$s_{4}$ & 0 & 0 & 0 & 0 & 1 & $21 / 3$ & 0 & $\begin{array}{ll}3 & 1 / 3 \\
\end{array}$ & 0 & 0 & -6 & $22 / 3$ \\
\hline$S_{8}$ & 0 & 0 & 0 & 0 & 0 & $14 / 9$ & 0 & $2 \quad 4 / 9$ & 1 & 0 & $-5 \quad 1 / 3$ & $15 / 9$ \\
\hline$S_{9}$ & 0 & 0 & 0 & 0 & 0 & $5 / 9$ & 0 & $15 / 9$ & 0 & 1 & $-4 \quad 2 / 3$ & $4 / 9$ \\
\hline$z$ & & 9 & 7 & 8 & 0 & 0 & 0 & 0 & 0 & 0 & 1 & 2233 \\
\hline$z-c$ & & 0 & 0 & 0 & 0 & 0 & 0 & 0 & 0 & 0 & 1 & \\
\hline
\end{tabular}

Dari tabel 4 di atas, diperoleh hasil optimum $x_{1}=47, x_{2}=62, x_{3}=172$ dan $z=2233$. Sehingga dapat disimpulkan berdasarkan metode Gomory Cut, perusahaan tersebut harus memproduksi senter A sebanyak 47, senter B sebanyak 62 dan senter C sebanyak 172 agar menghasilkan keuntungan optimum 2.233.000.

\section{KESIMPULAN}

Metode Branch and Bound dan Gomory Cut dapat digunakan untuk menyelesaikan masalah pemrograman linear integer. Berdasarkan contoh kasus yang diberikan, diperoleh hasil yang sama antara metode Branch and Bound dan Gomory Cut, yaitu perusahaan tersebut harus memproduksi senter A sebanyak 47, senter B sebanyak 62 dan senter C sebanyak 172 agar menghasilkan keuntungan optimum 2.233.000. Dalam proses penyelesaiannya, metode branch and bound memerlukan jumlah iterasi simpleks yang banyak dan waktu yang lama tapi lebih terjamin kekonvergenannya. 


\section{JURNAL SAINTIFIK VOL.2 NO.1, JANUARI 2016}

\section{DAFTAR PUSTAKA}

Anton, Howard dan Chris Rorres. 2005. Elementary Linear Algebra with Applications. Wiley, USA.

Bronson, Richard. 1982. Theory and Problems of Operations Research. McGraw-Hill, USA.

Dantzig, G.B. 1963. Linear Programming and Extensions. The Rand Corporation, USA.

Eiselt, H.A. dan C.L. Sandblom. 2007. Linear Programming and its Applications. Springer, Canada

Taha, Hamdy A.. 2007. Operations Research: An Introduction Eighth Edition. Prentice-Hall International Inc, New Jersey.

Winston, W.L.. 2003. Operations Research Aplications and Algorithm. Duxbury Press, USA. 